\title{
Models or strategies? On the perception of ambiguous words
}

Anzhelika Dubasova

Laboratory for Cognitive Studies, St. Petersburg State University, Russia

https://doi.org/10.36505/ExLing-2011/04/0016/000185

\begin{abstract}
Models of lexical ambiguity resolution differ mainly with respect to the role played by context in lexical access. In my paper I focus on two opposing views: those of autonomous access models (non-context-oriented) and selective access models (context-oriented). I analyse two types of situations of: a. the activation of a wrong meaning of an ambiguous word unpredictable from both models and b. humour based on puns. Proceeding from my analysis I propose to include "negative" factors (those leading to errors) and consider existing models as strategies, consequently, treating unsuccessful lexical ambiguity resolution as the influence of "negative" factors or as a selection of the wrong strategy.
\end{abstract}

Key words: lexical ambiguity, ambiguity resolution, meaning selection

\section{Introduction}

Although most words in any language have more than one meaning, we seem to have little difficulty understanding texts containing ambiguous words. It means that lexical ambiguity problems that we might experience get solved somehow. The question "how exactly?" encouraged a number of eye-tracking experiments (Duffy et al. (1988); Rayner \& Frazier (1989); Pacht \& Rayner (1993); Sereno et al. (2006); etc.) elucidating variables that affect the resolution of lexical ambiguity. The next stage in these studies was to develop theory about the mechanisms involved in ambiguity resolution. These theories differ mainly with respect to the role played by context in lexical access. I will focus on the two opposing views: those of autonomous access and selective access models (see e.g. Reichle et al. (2006); Vu et. al. (2000); Connine, Blasko, \& Wang (1994); Till, Mross, \& Kintsch (1988)).

The current models might reflect general mechanisms of ambiguous words' perception. However, it begs a question: since there are a number of lexical ambiguity resolution theories, doesn't it suggest the reference of a particular model to its own part of linguistic reality? To validate this suggestion we should demonstrate situations of lexical ambiguity perception being at variance with the assumptions of either of the models.

\section{a. The activation of a wrong meaning unpredictable from either of the models \\ Sample 1 [N 1] (translated from Russian, brackets and italics added). \\ "an examination period... I was standing on the platform at 4 a.m. and waiting for a train. Here it comes. The conductor says something about}

ExLing 2011: Proceedings of 4th Tutorial and Research Workshop on Experimental Linguistics, 25-27 May, Paris, France 
'билеты' [tickets | examination questions]. Without thought, I take my credit test book and offer it to her wondering : where are the 'билеты' [examination questions | tickets]?"

The Russian word "билет" is a biased ambiguous word with the dominant meaning of 'a document used to gain admission to a location or event; a passage ticket' (its frequency of occurrence is about $76 \%$ [N 2]). The meaning of 'examination card; examination questions' is one of the 3 subordinate meanings of the word, its frequency is about $4 \%$.

The situation (a railway station, a train, a conductor) unambiguously points to the dominant meaning of the word acting as a resolving context.

Neither autonomous access models nor selective access models can explain the activation of a wrong meaning here. The autonomous access models posit that all word meanings are exhaustively accessed at a rate that is proportional to their frequency, irrespective of context. Thus, the dominant (here, correct) meaning was to be activated in Sample 1. The selective access models posit that only the contextually appropriate meanings of ambiguous words are accessed at a rate that is proportional to their frequency (again it is the correct meaning that was to be activated).

I propose the following explanation of the error. Word meaning activation hardly occurs with all the other word meanings deactivated. Some meanings might have been activated before the actual process of word perception started. These create a "background" context for information processing. As a rule, the perception of ambiguous words is determined by resolving context and meaning frequencies and the "background" context does not influence word processing considerably. But in some cases the "background" context (thinking about exams in Sample 1) becomes stronger suppressing the "figure" (thoughts about a trip).

Samples of this type demonstrate a contradiction between the assumptions of the models and reality. However, the contradiction is smoothed over by including certain factors preventing the access of the appropriate meaning of an ambiguous word into the model. Let us treat this case as a competition between "positive" (ensuring successful perception) and "negative" (causing errors) factors. The "negative" factors can be roughly described as the above-mentioned "background" context, leading to a two-level competition, where the first is between the meanings of the ambiguous word (see e.g. Reichle et al. (2006)), and the second is between the factors affecting meaning selection (and thus, affecting previous level competition).

\section{b. Humour based on puns}

Sample 2 (translated from Russian, brackets and italics added).

"- Your breakfast, sir!

- Well, bacon, eggs, beans... and where is the toast ['тост']?

- To your health, sir!” 
An ambiguous word "тост" is also a biased one with the dominant meaning 'ceremonial act of drinking in honour of someone or something' (its frequency is about 96\%). It is important that, despite its high frequency, a listener/reader does not retrieve the dominant meaning (with the comical effect provided by unexpectedness). The prior context causes the retrieval of the subordinate meaning 'bread browned with dry heat' (its frequency is about $4 \%$ ). The example supports selective access models.

Sample 3 (translated from Russian, brackets and italics added).

"There is a board in our cafeteria where anyone can write his/her criticism of our cooking. Today there was an entry "the beans are too 'острый' [spicy | sharp]". I couldn't refrain from adding "and pricked my finger".

The Russian word 'острый' has 10 meanings, among them 'sharp' (with frequency about 13\%) and 'spicy' (with frequency about 3\%). This example supports autonomous access models.

Natural communication situations generate evidence for both opposing views. For this reason I suggest treating the existing models as strategies: "context-oriented vs. non-context-oriented", each responsible for its own "domain". Hence, we deal here with a three-level competition: a. between meanings of an ambiguous word, $b$. between the factors affecting meaning selection, and c. between the mentioned strategies (so that level $\mathrm{C}$ affects level B and level B affects level A).

\section{Summary}

Taking into account just "positive" factors would be idealistic, to an extent as they assume a listener / a reader free from any other preoccupation at the moment. Considering the "negative" factors would increase the explanatory power of these models, although treating models as strategies seems preferable here, since it allows the introduction of a concise model covering greater number of situation types. The suggested innovation could also explain misunderstanding as an effect of "negative" factors or a selection of a wrong strategy.

\section{Notes}

1. Most samples are from http://bash.org.ru/ (collection of quotes from ICQ, IRC, forums and everyday life); about 100 relevant samples were analysed.

2. Relative frequencies were assessed on the basis of a corpus search (Russian National Corpus http://ruscorpora.ru).

\section{Acknowledgements}

The research is supported by grants from Ministry of Education and Science of the Russian Federation (state contracts NN 16.740.11.0113, 02.740.11.0369), Russian Scientific Foundation for Research in Humanities (N 10-04-00056a). 


\section{References}

Connine, C.M., Blasko, D., Wang, J. 1994. Vertical similarity in spoken word recognition: Multiple lexical activation, individual differences, and the role of sentence context. Perception \& Psychophysics 56, 624-636.

Duffy, S.A., Morris, R.K., Rayner, K. 1988. Lexical ambiguity and fixation times in reading. Journal of Memory and Language 27, 429-446.

Pacht, J.M., Rayner, K. 1993. The processing of homophonic homographs during reading: Evidence from eye movement studies. Journal of Psycholinguistic Research 22, 251-271.

Rayner, K., Frazier, L. 1989. Selection mechanisms in reading lexically ambiguous words. Journal of Experimental Psychology: Learning, Memory, and Cognition 15, 779-790.

Reichle, E.D., Pollatsek, A., Rayner, K. 2006. Modeling the effects of lexical ambiguity on eye movements during reading. B.R.P. Van Gompel, M.F. Fischer, W.S. Murray, R.L. Hill (Ред.), Eye movements: A window on mind and brain (pp. 271-292). Oxford, England: Elsevier.

Sereno, S.C., O’Donnell, P.J.,Rayner, K. 2006. Eye movements and lexical ambiguity resolution: Investigating the subordinate bias effect. Journal of Experimental Psychology: Human Perception and Performance 32, 335-350.

Till, R.E., Mross, E.F., Kintsch, W. 1988. Time course of priming for associate and inference words in a discourse context. Journal of Verbal Learning and Verbal Behavior 16, 283-298.

Vu, H., Kellas, G., Metcalf, K., Herman, R. 2000. The influence of global discourse on lexical ambiguity resolution. Memory \& Cognition 28, 236-252. 